\title{
Numerical Study of 60 Strains of Serratia
}

\author{
By P. A. D. GRIMONT AND H. L. C. DULONG DE ROSNAY \\ Laboratoire de Bactériologie, Faculté de Médecine, 3, Place de la Victoire, \\ 33-Bordeaux, France
}

(Accepted for publication I8 April 1972)

\begin{abstract}
SUMMARY
A numerical study of 60 strains of Serratia showed three phena. Phenon A included 5I strains corresponding to the usual description of Serratia marcescens. Phenon B included five strains characterized by their fermentation pattern, positive malonate test and halotolerance. Phenon $\mathrm{C}$ included three aerogenic, cold-tolerant strains resembling pattern 2 of Fulton, Forney \& Leifson (I959). One strain did not fall into any of these phena. All strains of human origin fell into phenon A. This phenon could be subdivided into two smaller phena, one composed of haemolytic and multi-resistant nosocomial strains. A hypothetical median organism for phenon $\mathrm{A}$ is described.
\end{abstract}

\section{INTRODUCTION}

Over the last 20 years the taxonomy of the Serratia group has been drastically simplified. In the 4th edition of Bergey's Manual (1934) 27 species of Serratia were listed, whilst in the 7 th edition (1957) only five species were retained. Ewing, Davis \& Johnson (1962) suggested that all Serratia species could be described as a single species (Serratia marcescens) with one variety ( $S$. marcescens var. kiliensis). Martinec \& Kocur (1960, I961 $a, b, c)$ agreed with this conclusion.

Colwell \& Mandel (1965) subjected 33 strains of Serratia to Adansonian analysis and determined their deoxyribonucleic acid base composition. They concluded that there was only a single species in the genus Serratia. However, four strains differed from the homogeneous Serratia marcescens species group.

In our laboratory, some red pigmented isolates proved to differ from the present description of Serratia marcescens. A numerical study was then carried out on 60 strains of Serratia isolated from various sources.

\section{METHODS}

Strains used. A total of 60 strains (Table I) was used in the study. Strains were maintained on nutrient agar (meat extract, $3 \mathrm{~g}$; yeast extract, $3 \mathrm{~g}$; sodium chloride, $5 \mathrm{~g}$; Difco Bactopeptone, Io g; agar, $15 \mathrm{~g}$; and distilled water, I000 $\mathrm{ml} ; \mathrm{pH} 7 \cdot 4$ ).

Data collection and coding. A number of morphological, cultural and biochemical tests including tests of ecological significance (e.g. growth at $5{ }^{\circ} \mathrm{C}$ and $40{ }^{\circ} \mathrm{C}$, halotolerance, susceptibility to nine antibiotics) was applied. All tests (Grimont, I969) were at $30^{\circ} \mathrm{C}$ unless otherwise stated.

The following invariant characters were discarded: Gram-negative straight rods with rounded ends; not capsulated; peritrichous when motile; growth on nutrient agar at room temperature, $30^{\circ} \mathrm{C}, 37^{\circ} \mathrm{C}$; growth in alkaline broth ( $\mathrm{pH} \mathrm{9.2)}$ in I day; Christensen's citrate medium alkalinized; Kovacs' oxidase test negative; aerobic and anaerobic growth; catalase 
Table I. Strains of Serratia used in the numerical study

\begin{tabular}{|c|c|c|c|}
\hline No. & Original name and no. & Source & Pigment \\
\hline I & Serratia I-65 (LM)* & Blood & Red \\
\hline 2 & Serratia $12-65(\mathrm{LM})$ & Baker's dough & Red \\
\hline 3 & Serratia $17-65(\mathrm{LM})$ & Pus & None \\
\hline 4 & Serratia 18-65 (LM) & Urine & None \\
\hline 5 & Serratia $23-65$ (LM) & Sputum & Red \\
\hline 6 & Serratia $2-66$ (LM) & Urine & None \\
\hline 7 & Serratia 4-66 (LM) & Pus & None \\
\hline 8 & Serratia $7-66(\mathrm{LM})$ & - & Red \\
\hline 9 & Serratia io-66 (LM) & Sausage & None \\
\hline IO & Serratia I I-66 (LM) & Sputum & None \\
\hline II & Serratia 15-66 (LM) & Bone marrow & None \\
\hline I 2 & Serratia I9-66 (LM) & Blood & None \\
\hline 13 & Serratia $24-66$ (LM) & Urine & None \\
\hline 14 & Serratia $25-66$ (LM) & Blood & None \\
\hline 15 & Serratia $26-66(\mathrm{LM})$ & Urine & Red \\
\hline 16 & Serratia $72(B) *$ & Pig & Red \\
\hline 17 & S. plymuthicum 80 (B) & Urine & Red \\
\hline 18 & S. anolia 82 (B) & Stool & Red \\
\hline 19 & S. marcescens 83 (B) & Urine & Red \\
\hline 20 & S. plymuthicum 90 (B) & Pig & Red \\
\hline \multirow[t]{2}{*}{$2 \mathrm{I}$} & New species close to & & \\
\hline & S. marinorubra $232(\mathrm{~B})$ & Cow's-milk & Red \\
\hline 22 & S. kiliensis 658 (B) & Sea-water & Red \\
\hline 23 & S. kiliensis 782 (B) & Animal & Red \\
\hline 24 & S. kiliensis I694 (B) & Animal & Red \\
\hline 25 & S. marcescens 2029 (B) & Human & Red \\
\hline 26 & S. marcescens 2030 (B) & Human & Red \\
\hline 27 & S. marcescens 2032 (B) & Human & Red \\
\hline 28 & S. marcescens 2034 (B) & Human & Red \\
\hline 29 & S. marcescens 2187 (B) & Human & Red \\
\hline 30 & S. plymuthicum 2869 (B) & Human & Red \\
\hline $3 I$ & S. plymuthicum 3923 (B) & Sea-water & Red \\
\hline 32 & S. marcescens 2924 (B) & Sea-water & Red \\
\hline 33 & S. plymuthicum 3617 (B) & Sea-water & Red \\
\hline 34 & S. plymuthicum 3736 (B) & - & Red \\
\hline 35 & S. marcescens $3830(\mathrm{~B})$ & Sea-water & Red \\
\hline 36 & Santé Navale $\uparrow$ (Bordeaux) & Cultivated mushroom & Red \\
\hline 37 & Santé Navale (Bordeaux) & Cultivated mushroom & Red \\
\hline 38 & Santé Navale (Bordeaux) & Cultivated mushroom & None \\
\hline 39 & Santé Navale (Bordeaux) & Cultivated mushroom & Red \\
\hline 40 & Université II (Bordeaux) & Human & None \\
\hline $4 \mathrm{I}$ & Université II (Bordeaux) & Blood & None \\
\hline 42 & Université II (Bordeaux) & Human & None \\
\hline 43 & Université II (Bordeaux) & - & None \\
\hline 44 & Strain 'Mar...' (DR)*' & Throat & Red \\
\hline 45 & Strain 'Arb...' (DR) & Urine & None \\
\hline 46 & Strain 'C/D' (DR) & Urine & None \\
\hline 47 & Strain 'And...' (DR) & Pus & None \\
\hline 48 & Strain 'Per...'(DR) & Blood & None \\
\hline 49 & Strain 'Bay...' (DR) & Urine & None \\
\hline 50 & Strain 'C/B' (DR) & Urine & None \\
\hline $5 \mathrm{I}$ & Strain 'Dab...' (DR) & Urine & None \\
\hline 52 & Strain 'Cha...' (DR) & Urine & None \\
\hline 53 & Strain 'Deb...' (DR) & Urine & None \\
\hline 54 & Strain 'Beg...' (DR) & Urine & None \\
\hline 55 & Strain 'Ben...' (DR) & Urine & None \\
\hline 56 & Strain 'Arb...' (DR) & Urine & None \\
\hline 57 & Strain 'Eve...' (DR) & Blood & None \\
\hline 58 & Strain 'Bon...' (DR) & Urine & None \\
\hline 59 & Strain 'Cou...' (DR) & Bone marrow & None \\
\hline & Strain 'Das ' (DR) & Urine & \\
\hline
\end{tabular}

* $\mathrm{LM}=$ Professor Le Minor, Institut Pasteur, Paris. B $=$ Professor Brisou, University of Poitiers. DR = Professor Dulong de Rosnay, Hôpital Pellegrin, Bordeaux.

† Strains 'Santé Navale' have been isolated in Dr Desnues' laboratory. 
positive; nitrate reduction positive (nitrate broth, Griess' method); reduction of triphenyltetrazolium chloride; fermentation of glucose (Hugh \& Leifson's method); peptone water with Durham tube and carbohydrate or polyalcohol: acid from galactose (3 days), fructose, mannose, sucrose, trehalose, glycerol (3 days), mannitol, inositol, salicin ( 2 days), no acid from dulcitol; beta-galactosidase present; no gas produced when inositol is fermented; lysine decarboxylase (Falkow's medium without peptone); DNase positive (strongly or weakly); no production of indol (peptone water); no splitting of urea (Stuart's medium); no tryptophan deaminase; no arginine dihydrolase.

The following 55 tests remained in the numerical study: motility; size of colony, surface (S or $\mathrm{M}$ ); pigment formation on egg yolk agar, nutrient agar, Brain Heart Infusion agar; pellicle and ring in nutrient broth; growth at $5{ }^{\circ} \mathrm{C}$ and at $40^{\circ} \mathrm{C}$; growth in broth with $\mathrm{NaCl}$ $6.5 \%$ and $7.5 \%$; growth in $\mathrm{KCN}$ medium; growth in presence of Brillant Green $\mathrm{I} / 200000$, Crystal Violet I/I00000, thallium acetate I/5000: growth on Simmons's citrate; malonate broth becoming alkaline; carbohydrate fermentation: xylose, arabinose, rhamnose, galactose (quantitative result only), maltose, lactose (and ONPG test with and without prior induction), cellobiose, raffinose, glycerol (quantitative result only), sorbitol, adonitol, soluble starch, salicin (quantitative result only), aesculin hydrolysis, methyl-red reaction, gas in glucose; $\mathrm{H}_{2} \mathrm{~S}$ production (paper strip); gelatin (Frazier) and casein hydrolysis, coagulated serum liquefaction; decarboxylase reactions with ornithine, asparagine, histidine; haemolysis (horse blood); DNase (quantitative result only); lecithinase (lecithin agar); Tween-esterase; resistance to the following antibiotics: ampicillin, streptomycin, kanamycin, chloramphenicol, erythromycin, tetracycline, colistin, nalidixic acid, gentamycin.

Multi-state characters were turned into several two-state characters and were encoded following the non-additive procedure (Sneath, 1957) and using Adansonian principles.

Computation of similarities. For estimating overall similarity, the Jaccard-Sneath coefficient (Sneath, 1957) excluding negative matches was used. A program for computation of similarities was written in Fortran IV and data were processed through an IBM 360/44 machine.

Cluster analysis. Two clustering methods were used: the single linkage method (Sneath, I957) and the weighted pair group method (Sokal \& Sneath, 1963). Dendrograms were constructed from the results of the clustering procedures.

Taxometric maps were designed following two methods. The first one is Carmichael \& Sneath's (1969): clusters are represented by circles whose diameter is the same as the distance between the two most distant points in the cluster. The distance between the closest neighbours in two clusters is represented by a line connecting the margins of the two circles. The second method is modified from Lysenko \& Sneath (1959): a cluster is represented by a circle whose diameter is the same as the complement of the mean intragroup similarity. Centre to centre distance between two circles is the complement of the mean intergroup similarity.

For the largest phenon a hypothetical median organism was calculated according to the method of Liston, Wiebe \& Colwell (I963): the mean number ( $n$ ) of positive characters occurring in the phenon is determined and characters are ranked according to their frequency of occurrence. The median organism will possess the characters which occur in most of the strains in the phenon, i.e. the $n$ most frequent characters.

\section{RESULTS}

The dendrograms obtained from the single linkage method and from the weighted pair group method are given respectively in Fig. I and Fig. 2. Both are roughly similar. As can be seen, 59 organisms fell into three phena while one strain was distinct from them. For convenience, the phena were called A, B and C. Phenon A contains 5I strains, phenon B 


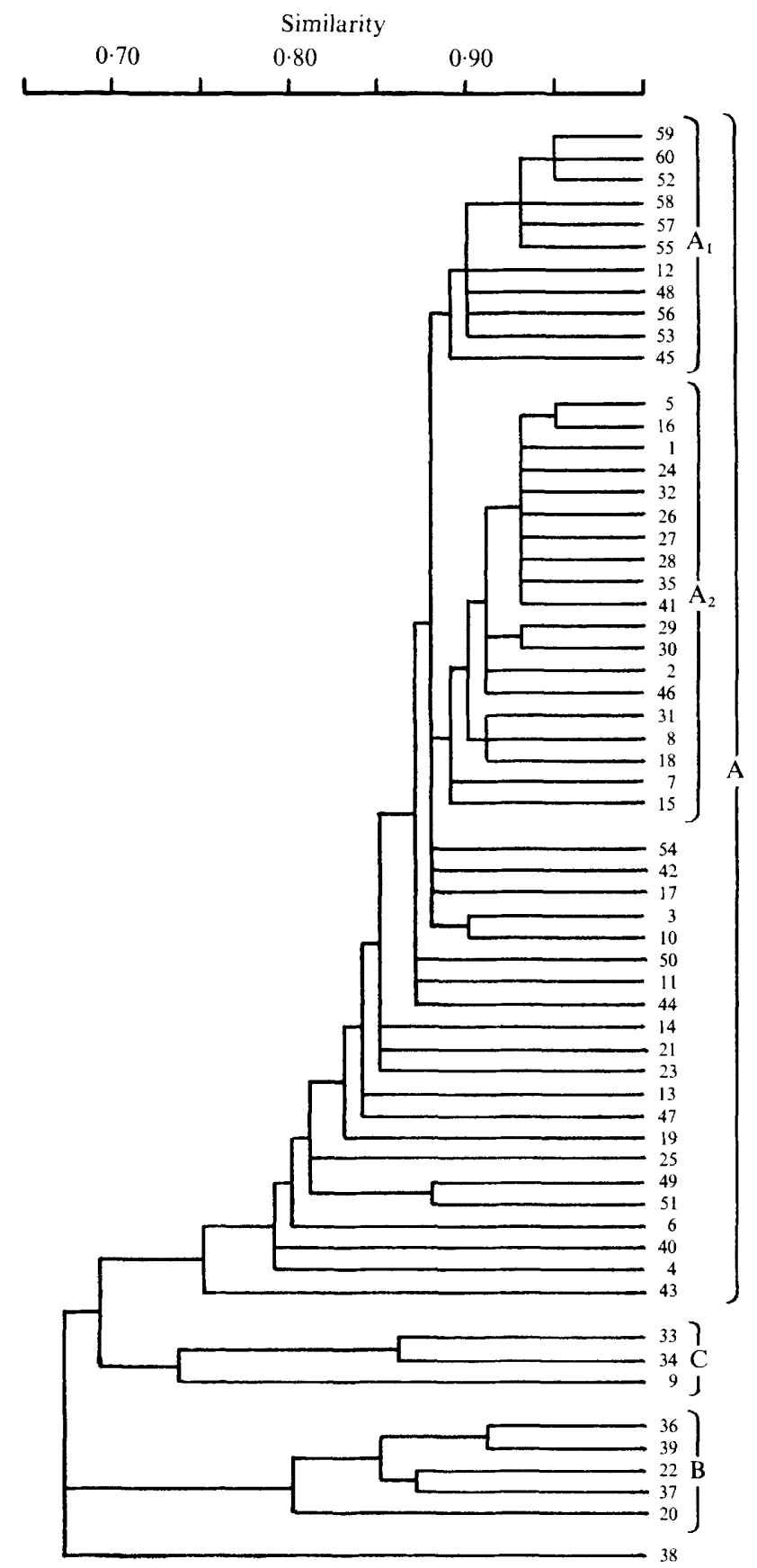

Fig. I. Dendrogram constructed by the single linkage method.

contains five strains, while phenon $\mathrm{C}$ contains only three strains. Strain 38 stood apart from all three phena. The homogeneity of these clusters was checked by calculating mean intragroup similarities. Relationships between clusters were evaluated by calculation of mean intergroup similarities. Mean $S$ values (mean similarities) are given in Table 2. 


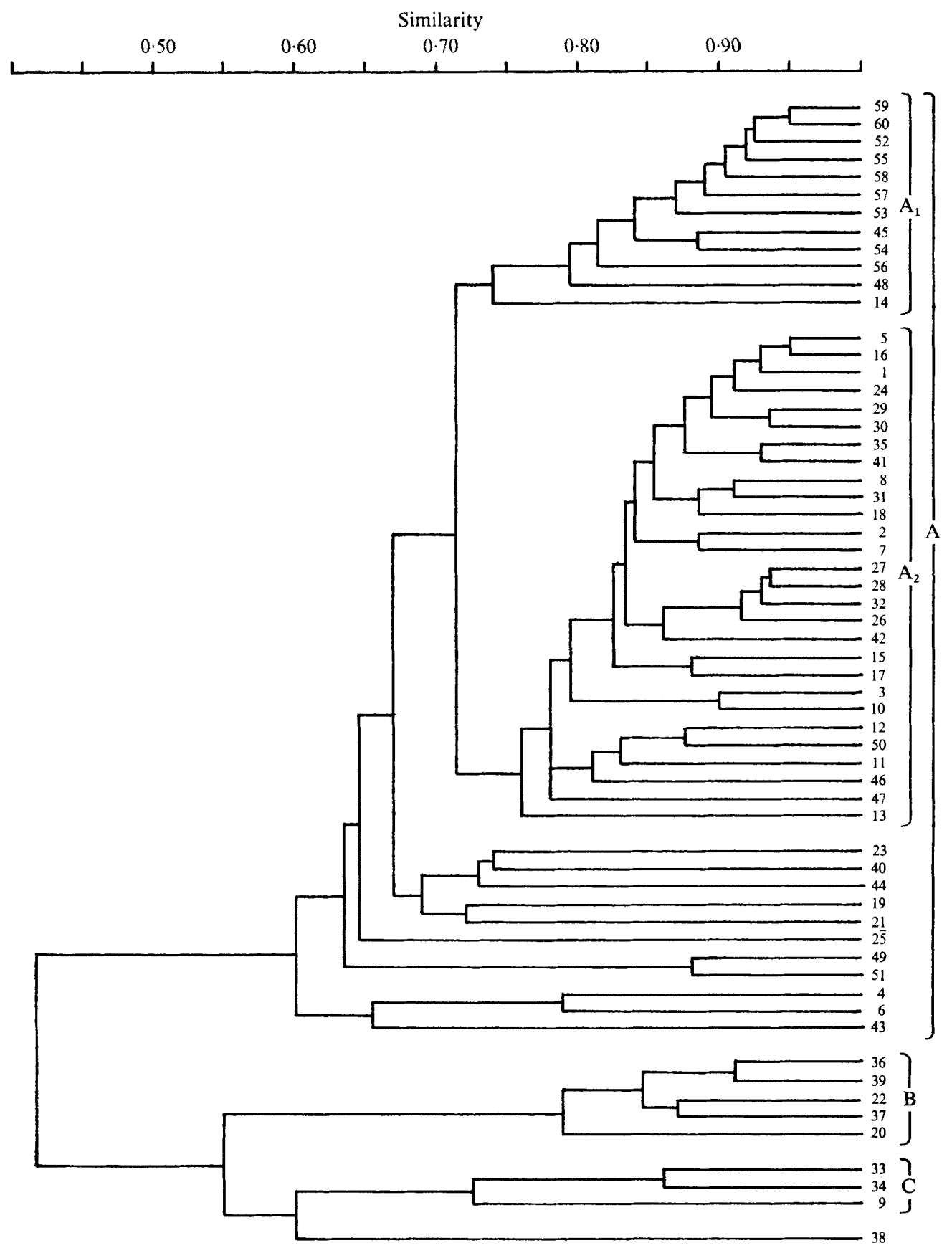

Fig. 2. Dendrogram constructed by the weighted pair group method.

The homogeneity and individuality of the three phena are illustrated by two taxometric maps (Fig. 3a,b). Fig. 3(a) was constructed by taking into account the extreme distances (largest distance within a phenon, shortest between phena) following Carmichael \& Sneath (I969). Fig. $3(b)$ was constructed using average distances (I $-S)$. Both maps, although 
(a)

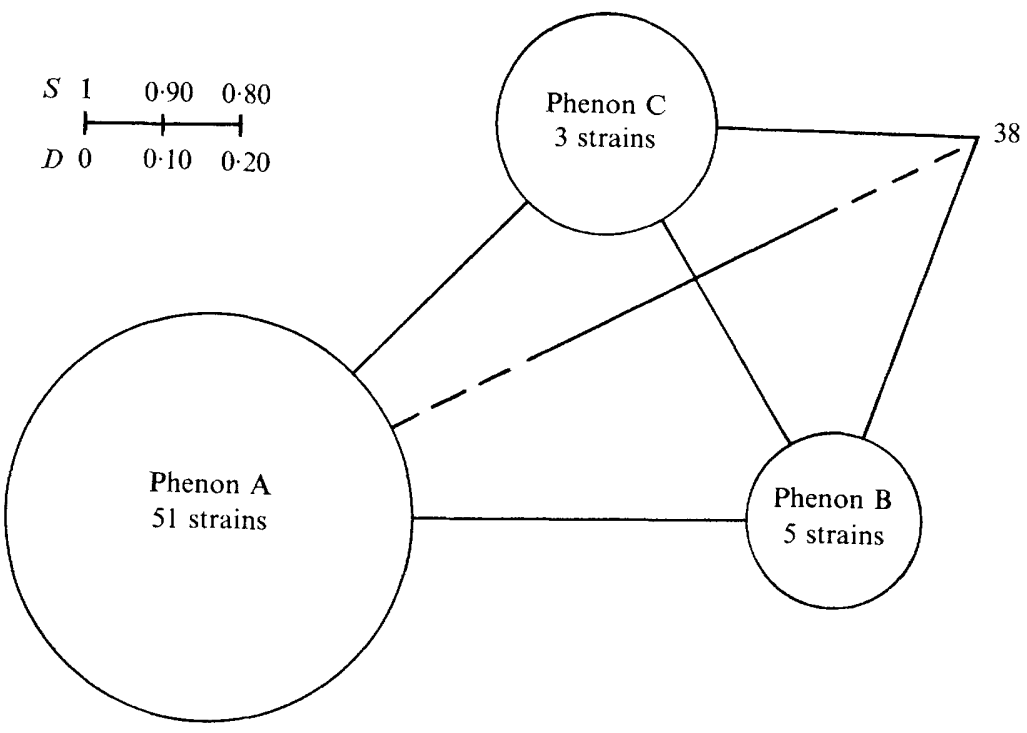

(b)
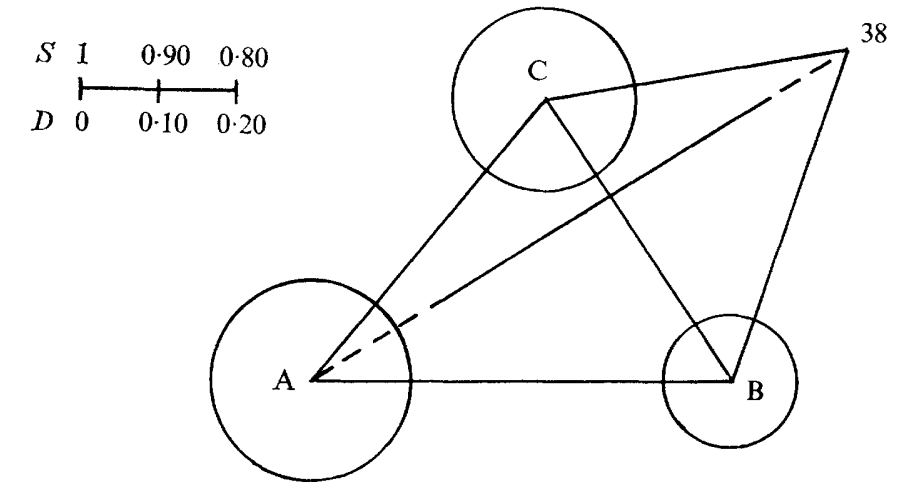

Fig. 3. Taxometric maps constructed by the methods of (a) Carmichael \& Sneath (1969) and (b) Lysenko \& Sneath (1959) modified.

\section{Table 2. Intra- and intergroup mean $S$ values}

$\begin{array}{cccc}\text { A } & 0.75 & & \\ \text { B } & 0.47 & 0.83 & \\ \text { C } & 0.54 & 0.57 & 0.77 \\ 38 & 0.49 & 0.55 & 0.61 \\ & \text { A } & \text { B } & \text { C }\end{array}$

based on different methods, give the same overall results. They are useful in interpreting the dendrograms.

The average of the mean intergroup distances (mean $\mathrm{I}-S$ ) is 0.46 . One can say that the centres of phena A, B, C and strain 38 are roughly equidistant and delimit a tetrahedron with sides $0.46 \pm 0.07$ units long. The most useful characters for differentiation of phena $A$, $\mathrm{B}, \mathrm{C}$ and strain 38 are listed in Table 3 . 
Table 3. Interphenon differentiating characteristics

\begin{tabular}{|c|c|c|c|c|}
\hline & \multicolumn{4}{|c|}{ Phena } \\
\hline & A & B & $\mathrm{C}$ & 38 \\
\hline Pigment production & $22 *$ & $5^{*}$ & $2^{*}$ & $0^{*}$ \\
\hline Growth at $5^{\circ} \mathrm{C}$ & 0 & 0 & 3 & I \\
\hline Growth at $40^{\circ} \mathrm{C}$ & 36 & 0 & o & I \\
\hline $\mathrm{NaCl} 6.5 \%$ (I day) & 0 & 5 & 0 & 0 \\
\hline $\mathrm{NaCl} 7 \cdot 5 \%$ & 0 & 4 & 0 & 0 \\
\hline Gas from glucose & 0 & 0 & 3 & 0 \\
\hline \multicolumn{5}{|l|}{ Acid from: } \\
\hline Adonitol (I day) & 0 & 5 & 0 & 0 \\
\hline Adonitol (3 days) & $5 \mathrm{I}$ & 5 & 0 & I \\
\hline Arabinose & 0 & 5 & 3 & I \\
\hline Cellobiose (I day) & o & 5 & 2 & I \\
\hline Cellobiose ( 3 days) & 5 & 5 & 2 & I \\
\hline Glycerol: $\mathrm{pH} 5.8$ in I day & 50 & 0 & 2 & o \\
\hline $\begin{array}{l}\mathrm{pH} 5.8 \text { in } 3 \text { days } \\
\text { pH } 6.4 \text { to } 6.7\end{array}$ & 50 & o & 3 & I \\
\hline in 3 days & I & 5 & 0 & 0 \\
\hline Lactose (I day) & 0 & 5 & 0 & o \\
\hline Raffinose (I day) & o & 5 & 3 & I \\
\hline Raffinose ( 2 days) & I & 5 & 3 & I \\
\hline Rhamnose & 0 & 0 & 0 & I \\
\hline Sorbitol & 49 & 0 & 3 & I \\
\hline Xylose & 0 & 5 & 3 & I \\
\hline Ornithine decarboxylase & 49 & 0 & I & $\mathrm{I}$ \\
\hline Casein hydrolysed (I day) & 40 & 0 & I & 0 \\
\hline (3 days) & 46 & 0 & 2 & o \\
\hline (5 days) & 48 & I & 3 & o \\
\hline Lecithin-agar & 48 & 5 & 3 & o \\
\hline Tween 80 & $5 \mathrm{I}$ & 5 & 3 & o \\
\hline Malonate & 0 & 5 & 0 & o \\
\hline Haemolysis (horse blood, I day) & 9 & 0 & 0 & o \\
\hline Growth on thallium acetate & 50 & 3 & o & o \\
\hline Growth on tetracycline $5 \mu \mathrm{g} / \mathrm{ml}$ & 45 & 0 & o & o \\
\hline
\end{tabular}

* No. of positive strains.

Phenon A. Strains of this phenon did not ferment pentoses, raffinose and rhamnose. Gas was not produced during fermentation of sugars. A very tiny bubble of gas could be seen irregularly and was not taken into account. Most strains fermented sorbitol and possessed ornithine decarboxylase. Malonate broth did not become alkaline. Most strains were tetracycline resistant. All human strains (42) fell into phenon A. The other sources were as follows: four strains isolated from animals, three isolated from sea-water, one from food and one of unknown origin.

A hypothetical median organism for phenon A, calculated according to Liston et al. (1963), possesses the following characters: motile; colony 2 to $5 \mathrm{~mm}$; S colony form; pigment production on egg-yolk agar; ring in broth, no pellicle; growth at $40{ }^{\circ} \mathrm{C}$ but not at $5{ }^{\circ} \mathrm{C}$; growth in $\mathrm{NaCl} 6.5 \%$ (2 days) but not in $\mathrm{NaCl} 7.5 \%$; growth in $\mathrm{KCN}$ medium; growth on Crystal Violet I/100000; growth on thallium acetate I/5000 (2 days); growth on Simmons's citrate; malonate broth negative; fermentation of galactose (I day), maltose, glycerol (I day), sorbitol, adonitol (3 days), soluble starch, salicin (I day); no fermentation of xylose, arabinose, rhamnose, cellobiose, raffinose, lactose (I day); gas not produced from glucose; beta-galactosidase may be inducible or constitutive; aesculin hydrolysed; methyl- 
red reaction negative; $\mathrm{H}_{2} \mathrm{~S}$ not produced; gelatin hydrolysed (I day); coagulated serum liquefied in less than 5 days; casein hydrolysed (I day); decarboxylation of ornithine, asparagine, histidine; hot-cold haemolysis of horse blood (not in I day at $30{ }^{\circ} \mathrm{C}$ ); DNase positive (I day); precipitation around colony on lecithin agar; precipitation around colony on Tween 80 agar ( $\mathrm{I}$ day); minimal inhibitory concentrations with the following antibiotics: ampicillin (over $5 \mu \mathrm{g} / \mathrm{ml}$ ), streptomycin (over $100 \mu \mathrm{g} / \mathrm{ml}$ ), kanamycin (less than $5 \mu \mathrm{g} / \mathrm{ml}$ ), chloramphenicol ( 5 to $15 \mu \mathrm{g} / \mathrm{ml}$ ), erythromycin (over $50 \mu \mathrm{g} / \mathrm{ml}$ ), tetracycline (over $5 \mu \mathrm{g} / \mathrm{ml}$ ), colistin (over $100 \mu \mathrm{g} / \mathrm{ml}$ ), nalidixic acid (less than $5 \mu \mathrm{g} / \mathrm{ml}$ ), gentamycin (0.I to I $\mu \mathrm{g} / \mathrm{ml}$ ). The similarity coefficients between the hypothetical organism and every organism of phenon A were calculated. $S$ values ranged from 0.97 (strain 5) to 0.63 (strain 4). All but one strain showed similarities to the median $>0.70$. Forty-four strains showed $S$ values $\geqslant 0.80$, and I 8 strains $\geqslant 0.90$. Strain 4 , having a low similarity with the median organism seems misplaced in phenon A.

On both dendrograms, two subgroups, referred to as $A_{1}$ and $A_{2}$, are distinguishable within phenon $A$, but their memberships differ somewhat between the two dendrograms.

With the single linkage (Fig. I) subgroup $A_{1}\left(A_{1} / S L\right)$ consists of I I strains. All were human strains. Ten of them came from the same hospital in Bordeaux. Seven were strongly haemolytic on horse blood and all were multi-resistant to antibiotics. Ten strains could grow at $40{ }^{\circ} \mathrm{C}$. None was pigmented. With the average linkage (Fig. 2) subgroup $\mathrm{A}_{1}\left(\mathrm{~A}_{1} / \mathrm{AL}\right.$ ) consists of 12 strains of human origin. Eleven of them were isolated in the same hospital in Bordeaux. All could grow at $40^{\circ} \mathrm{C}$.

With the single linkage, subgroup $\mathrm{A}_{2}\left(\mathrm{~A}_{2} / \mathrm{SL}\right)$ consists of 19 strains. With the average linkage, $A_{2} / A L$ consists of 28 strains. All I9 strains of $A_{2} / S L$ are included in $A_{2} / A L$. The typical strain 5 was at the starting-point of the subgroup formation. As the level of clustering decreased, fewer organisms joining the cluster were pigmented. At level 0.82, $\mathrm{A}_{2} / \mathrm{AL}$ consisted of 20 strains, 17 of which were pigmented. At level $0 \cdot 75,17 / 28$ strains only were pigmented. At level $0.60,22 / 5$ I strains clustered were pigmented (in phenon A).

Subgroups $A_{1}$ and $A_{2}$ are then essentially differentiated by pigmentation, susceptibility to antibiotics and haemolysis.

Phenon $B$. This phenon consists of five non-human strains. Three were isolated from cultivated mushrooms, one from sea-water and one from a pig. All were pigmented and fermented pentoses, raffinose, cellobiose, lactose and adonitol, but not sorbitol. Malonate broth became alkaline. They were also characterized by halotolerance, no growth at $5{ }^{\circ} \mathrm{C}$ and $40{ }^{\circ} \mathrm{C}$, lack of ornithine decarboxylase and by susceptibility to tetracycline.

Phenon $C$. This phenon consists of three non-human strains. One was isolated from seawater, one from sausage, and one was of unknown origin. Pentoses, raffinose and sorbitol were fermented but not adonitol. Gas was produced during fermentation of all sugars and polyalcohols except inositol. Growth occurred at $5{ }^{\circ} \mathrm{C}$ but not at $40^{\circ} \mathrm{C}$. All three strains were susceptible to tetracycline.

Strain 38 . This aberrant strain was isolated from a cultivated mushroom. It fermented pentoses, raffinose, cellobiose, sorbitol and rhamnose. It was susceptible to tetracycline but lacked Tween-esterase. While Serratia strains usually have a fishy odour (like trimethylamine), this strain had an odour like soya sprouts.

Differences between phena were emphasized by the numerical method, but one must keep in mind that all 60 strains in this study share in common the numerous invariant characters described above (see Methods), but not included in the computer analysis. Furthermore, some tests were positive for all but one strain (atypical strain falling in phenon A): growth on KCN medium (strain 4), Simmons's citrate (strain 4), fermentation of soluble 
starch (strain 25). Some tests were positive for all but two strains: fermentation of galactose (strains 49 and 5I), fermentation of maltose (strains 25 and 29), DNase (doubtful for 47 and 5I). Some tests were positive for all but three strains: gelatin hydrolysis (doubtful for 43, 49, 5I), liquefaction of coagulated serum (strains 25, 49, 5I). As can be seen (Fig. I, 2), all of these infrequent results were given by marginal organisms of phenon $\mathrm{A}$.

\section{DISCUSSION}

It appears from the present study that the concept of a single Serratia species is the product of an oversimplification and that at least three taxa can be recognized.

Phenon A resembles Serratia marcescens of Ewing et al. (1962) and the single phenon of Colwell \& Mandel (1965) and biotype I of Bascomb, Lapage, Willcox \& Curtis (197I) very closely. It also resembles pattern I of Fulton et al. (I959) except that cellobiose is not readily fermented by our strains.

Phenon B is not described by Ewing et al. (1962). It is different from pattern 2 of Fulton et al. (1959), strains of phenon B fermenting adonitol readily and being anaerogenic. Phenon B and biotype II of Bascomb et al. (I97I) share many characteristics. However, they differ in some respects (malonate, lysine decarboxylase tests, fermentation of sorbitol).

Phenon $\mathrm{C}$ resembles pattern 2 of Fulton et al. (1959) in producing acid from the same sugars and not from adonitol, and in producing gas from glucose. It differs only in gelatin hydrolysis, but a different method was used. Strains of phenon C, if we except pigmentation, also resemble strains of Enterobacter liquefaciens by giving the same biochemical reactions (Edwards \& Ewing, I962) and being cold-tolerant mesophiles (Grimes, I96I). Non-pigmented strains of this group could certainly be classified as Enterobacter liquefaciens.

Strain 38 does not fit any published description.

Fulton et al. (I959) observed that their 'pattern I strains... are the ones to be expected from clinical sources' and 'a different Serratia, not so far encountered in clinical materials, is also described'. We can extend their statement to our results. As we have pointed out, all the strains isolated from humans fell into phenon A. Strains of phena B and C did not grow at $40^{\circ} \mathrm{C}$; this may account for the rare occurrence of these strains in clinical materials.

The differentiating tests listed in Table 3 were applied to three reference strains recently received from P. H. A. Sneath. We may say that working type strain D3I8 (NCTCI377) corresponds to the description of phenon A. Strain D3I7 (NCTC 9493) corresponds to the description of phenon C. These two strains were included in the study of Bascomb et al. (197I) and were placed as follows: strain NCTC I 377 was in their biotype I and strain NCTC 9493 stood apart from this biotype. A third strain, DI19, labelled 'Serratia marinorubra type strain' seems to fit with the description of our phenon B.

The splitting of phenon A in two smaller phena is less clear and these subgroups may overlap. A study in progress in our laboratory is revealing that most strains of subgroup $A_{1}$ carry R factors. The question may be asked: 'are not these subgroup $A_{1}$ strains identical?' However unpublished data on phage sensitivity, R-factor transfer, colicinogeny and biochemical tests, do not allow the reduction of the 12 strains of subgroup $A_{1}$ to less than ten epidemiological entities.

Another problem is whether or not we may include in a taxometric study some features given by plasmids. In fact we know that resistance to antibiotics may be due to plasmids in this study, but we do not know if other features are also plasmid-linked. Our opinion is that a phenetic classification must rely on the phenotype of organisms regardless of the location of genes (a situation which is not immutable). We do not yet have enough genetic knowledge. 
Therefore, the existence of a subgroup $\mathrm{A}_{1}$ 'plasmid-made' may represent the evolution of the classical Serratia marcescens species towards an 'iatrogenic' variety.

The authors wish to thank Professor J. Brisou and Professor Le Minor who provided many strains, and Dr S. P. Lapage and Professor P. H. A. Sneath for their help and advice. Thanks are also due to Mr Pasco who computed the similarity coefficients.

\section{REFERENCES}

Bascomb, S., Lapage, S. P., Willcox, W. R. \& Curtis, M. A. (1971). Numerical classification of the tribe Klebsielleae. Journal of General Microbiology 66, 279-295.

Bergey's Manual of Determinative Bacteriology (1934), $4^{\text {th }}$ edn.; (1957) 7 th edn. Baltimore: Williams and Wilkins.

Carmichael, J. W. \& Sneath, P. H. A. (1969). Taxometric maps. Systematic Zoology r8, 402-415.

Colwell, R. R. \& MANDEL, M. (1965). Adansonian analysis and deoxyribonucleic acid base composition of Serratia marcescens. Journal of Bacteriology 89, 454-46r.

EDWARDS, P. R. \& EWING, W. H. (I962). Identification of Enterobacteriaceae, 2nd edn. Minneapolis: Burgess Publishing Co.

Ewing, W. H., Davis, B. R. \& Johnson, J. G. (1962). The genus Serratia: its taxonomy and nomenclature. International Bulletin of Bacteriological Nomenclature and Taxonomy 12, 47-52.

Fulton, M., Forney, C. E. \& Leifson, E. (1959). Identification of Serratia occurring in man and animals. Canadian Journal of Microbiology 5, 269-275.

GrImes, M. (196r). Classification of the Klebsiella-Aerobacter group with special reference to the coldtolerant mesophilic Aerobacter types. International Bulletin of Bacteriological Nomenclature and Taxonomy II, II I-I 29.

Grimont, P. A. D. (1969). Les Serratia: étude taxométrique. Thèse de Médecine, Faculté de Médecine de Bordeaux.

Liston, J., Wiebe, W. \& Colwell, R. R. (1963). Quantitative approach to the study of bacterial species. Journal of Bacteriology 85, $106 \mathrm{I}-1070$.

Lysenko, O. \& SNEATH, P. H. A. (1959). The use of models in bacterial classification. Journal of General Microbiology 20, 284-289.

Martinec, T. \& Kocur, M. (1960). The taxonomic status of Serratia plymuthica (Lehmann and Neumann) Bergey et al. and of Serratia indica (Eisenberg) Bergey et al. International Bulletin of Bacteriological Nomenclature and Taxonomy 10, 247-254.

Martinec, T. \& Kocur, M. (I96ra). The taxonomic status of Serratia marcescens Bizio. International Bulletin of Bacteriological Nomenclature and Taxonomy II, 7-I2.

Martinec, T. \& Kocur, M. (I96I $b$ ). A taxonomic study of the members of the genus Serratia. International Bulletin of Bacteriological Nomenclature and Taxonomy II, 73-78.

MARTINeC, T. \& Kocur, M. (196I $c$ ). Contribution to the taxonomic studies of Serratia kiliensis (Lehmann et Neumann) Bergey. International Bulletin of Bacteriological Nomenclature and Taxonomy rr, 87-90.

Sokal, R. R. \& Sneath, P. H. A. (1963). Principles of Numerical Taxonomy. San Francisco \& London: W. H. Freeman.

SNEATH, P. H. A. (1957). The application of computers to taxonomy. Journal of General Microbiology $\mathbf{7} 7$, $20 \mathrm{I}-226$. 